\title{
The Advent of E-Health
}

\author{
How Interactive Media Are Transforming Health Communication
}

Linda Neuhauser / Gary L. Kreps

Die Weltgesundheitsorganisation schätzt, dass die Hälfte der Krankheiten und Behinderungen in den industrialisierten Ländern auf Risikofaktoren wie das Rauchen, wenig Bewegung und die Ernährung zurückzufübren ist. Maßnabmen der Gesundheitskommunikation haben gezeigt, dass sie großen Einfluss auf Gesundheitsverhaltensweisen haben können. Um den Erfolg dieser Maßnabmen jedoch auf breiter Bevölkerungsbasis zu erböhen, müssen interpersonale und durch Massenmedien übertragene Kommunikationsstrategien verbunden werden. E-Health-Kommunikation über Computer und andere digitale Technologien könnte die traditionellen und neuen Medien verbinden, fördern und "personalisieren". In Experimentalstudien haben E-Health-Maßnabmen unter Einbezug verschiedener Medien ergeben, dass sich das Verhalten deutlich verbesserte. Der Langzeiterfolg solcher Multimedia-Gesundheitskommunikationsmaßnabmen wird weitere Anstrengungen zur Zusammenarbeit, spürbare Forschung und die Entwicklung neuer Kommunikationsstragien erfordern. Dieser Beitrag beschreibt die Entwicklung der E-Health-Kommunikation, bietet erste empirische Beweise für deren Wirksamkeit auf das Verbalten und empfieblt Strategien, mit Hilfe derer E-Health-Maßnahmen in der nationalen and internationalen Gesundheitsförderung angewandt werden können.

Keywords: E-Health, Gesundheitskommunikation, Online-Gesundheitskommunikation, Internet Gesundheitskommunikation, Gesundheitsinformatik, Gesundheitsverhalten, Gesundheitsmaßnahmen, Gesundheitsmedien

\section{Health Communication and Population Health}

In late 2002, the World Health Organization (WHO) published a landmark report on the global burden of disease, disability and death (WHO, 2002). The World Health Report concludes that the much of ill health can be attributed to a relatively small number of risk factors. In industrialized (“developed”) countries, ten risk factors are thought to account for about half of the disease burden (Figure 1).

Intriguingly, all of these factors are behavioral-they result from people's choices. Similarly, a US report estimated that one-half of all deaths each year are attributed to preventable behavioral factors such as unhealthy diets, smoking, alcohol abuse, and inadequate exercise (McGinnis \& Foege, 1993). Such analyses have led many countries to define population health goals, many of which involve promoting healthier behaviors. Examples include the US Healthy People 2010 Report, the Canadian Framework for Health and the World Health Organization's report on Health Promotion: Milestones on the Road to a Global Alliance (USDHHS, 2000; Epp, 1986; WHO, 1998).

The challenge to effect behavior change in global populations is staggering. Although we have substantial epidemiological evidence that behavior change can greatly improve health, we have a long way to go to achieve the desired outcomes. The World Health Organization Report and the national health frameworks propose that health communication be the primary strategy to influence people's behavior. This paper describes current health communication approaches, and how interactive media ("e-health") can add to their power to improve population health. 
Figure 1: Burden of disease attributable to 10 leading risk factors in developed countries*

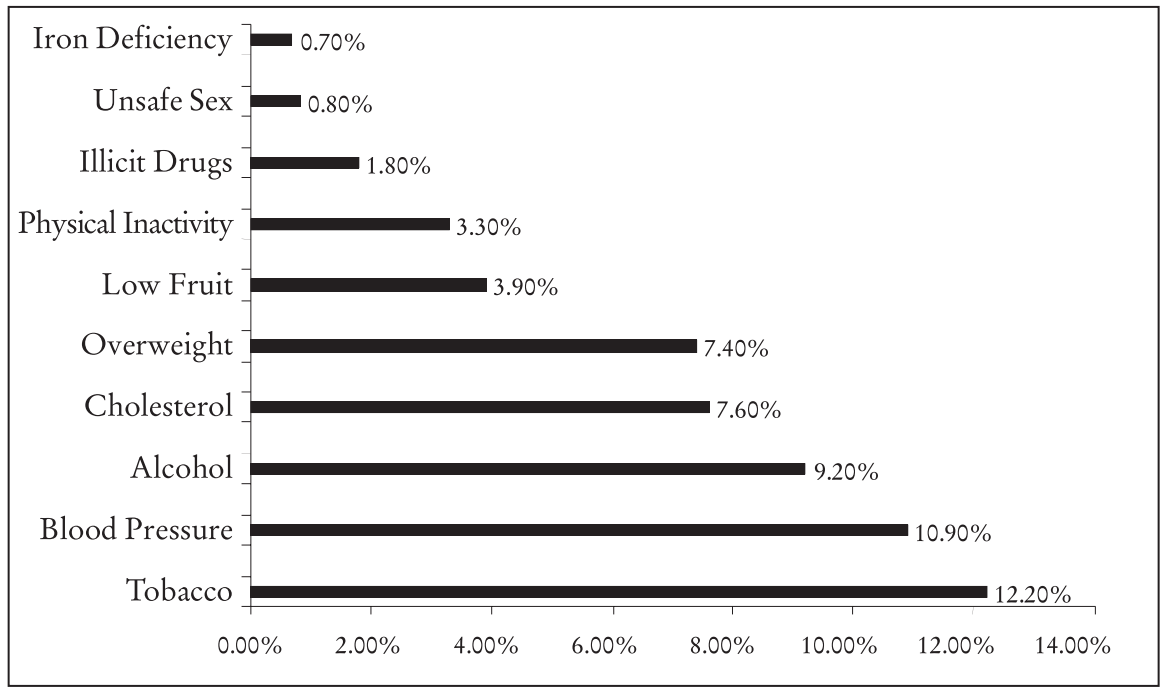

Percentage represents lost healthy years by each risk factor

*Adapted from World Health Report 2002, Figure 4.10, p. 83 (WHO, 2002).

\section{Health Behavior Models and Communication Interventions}

\subsection{Models}

Models of behavior change provide the framework upon which health communication interventions can be based. Classic models include the Health Belief Model, the Precaution Adoption Process Model, the Theory of Reasoned Action, the Transtheoretical Model, Learning and Conditioning, Social Learning Theory, Decision-Making Theory, and Diffusion of Innovations (for reviews see: the Institute of Medicine's report on Health and Behavior, 2001; and Ferguson, 1998). These models draw on knowledge from the fields of communication, psychology, sociology, and medicine and from literatures on relational communication, persuasion, and social marketing (Kreps, Bonaguro, \& Query, 1998).

Despite many differences, the models are generally intended to predict and explain changes in individual health behaviors mediated through psychological variables. For example, the Transtheoretical Model identifies "stages of change" in which a person moves from "precontemplation" to "action" to "maintenance" of a behavior change such as quitting smoking. According to this model, communication approaches should be tailored to a person's level of readiness to change. The Health Belief Model assesses a person's likelihood of undertaking a preventive health behavior based on the person's perceptions of susceptibility to disease, benefits of the proposed action, and barriers to making the change. Thus, models have tended to focus on the individual as decisionmaker, rather than on the influence of the larger social context (Airhihenbuwa \& Obregon, 2000; Ferguson, 1998; Yoder et al., 1996). Of the aforementioned models, only the 
Theory of Reasoned Action and the Diffusion of Innovations include variables related to the influence of "important others" (Weinstein, 1993; Rogers, 1995).

More recently, there has been a movement from more psychologically oriented models to socio-psychological models (Bunton, Murphy \& Bennett, 1991). As behavioral science incorporates concepts from social theory and social epidemiology, there has been a major shift in health promotion toward a social ecological paradigm that acknowledges the powerful effects of social, institutional and cultural contexts on individual behavior (Stokals, 2000). The framework provides guidance for interventions at the intrapersonal, interpersonal, organizational, community and policy levels (see Emmons, 2000, p. 277).

\section{Health Communication Interventions and Outcomes}

A large body of health communication literature has demonstrated the powerful influences of communication interventions on a broad range of health behaviors and health outcomes. For example, Kreps and O’Hair (1995) report a series of studies showing the influences of intrapersonal, interpersonal, group, organizational, and societal communications on health knowledge, behaviors, and outcomes. Similarly, Greenfield, Kaplan, and Ware (1985) demonstrate the positive influences of increased patient communicative involvement in treatment on desired health outcomes. Dearing, Rogers, Meyer, Casey, Rao, Campo, and Henderson (1996) illustrate the successful effects of social marketing and diffusion-based strategies in encouraging at-risk populations to adopt important prevention behaviors. Large-scale longitudinal communication intervention programs, such as the Stanford Five City Heart Health Program and the Minnesota Heart Health communication program demonstrate the impact of these campaigns on promoting adoption of lifestyle changes to prevent cardiovascular disease and reducing gaps in public health knowledge (Flora, Maccoby, \& Farquhar, 1989; Pavlik, Finnegan, Strickland, Salman, Viswanath, \& Wackman, 1993).

In a recent review of the literature, Kreps and Chapelsky Massimilla (2002) examined published research from 1990-2000 on cancer communications that provide strong outcome data on the effectiveness of strategic communications in cancer control. The studies were examined across six topic areas based on the communications strategy used and behavior targeted: 1) strategic communications on adoption of prevention behaviors in diverse populations; 2) strategic communications on promotion of cancer detection and screening behaviors; 3 ) tailored communications on promotion of cancer prevention and control; 4) tailored communications on promotion of screening and detection behaviors; 5 ) interpersonal communications on provision of social support to cancer patients; and 6) social-marketing and diffusion-based communications encouraging at-risk populations to adopt prevention behaviors. This review clearly illustrated that many of the health communication interventions led to important cancer control and prevention outcomes. The review also showed that past research provides a large body of evidence that new communication technologies and an enhanced understanding of the communication needs of targeted audiences can significantly alter health behaviors associated with cancer risk reduction.

Yet, health communication efforts, despite their many individual successes, have often failed to demonstrate significant effects on population health outcomes. For example, Snyder \& Hamilton (2002) found many disappointing outcomes in their metaanalysis of US health campaigns. Overall, there has been only modest progress towards achieving the national US goals for health behavior change (National Center for Health 
Statistics, 1996). It is our view that traditional health communication is frequently insufficient to engage people to change behavior within the complex contexts of their lives. "E-health communication," health promotion efforts that are mediated by computers and other digital technologies may have great potential to promote desired behavior changes through unique features such as mass customization, interactivity, and convenience. However, we have much to learn about whether the technical promise of ehealth communication will be effective within the social reality of how diverse people communicate and change in the modern world (Neuhauser \& Kreps, 2003).

\section{Improving Health Communication}

The uneven results of health communication interventions have been a source of intense scrutiny leading to the following suggestions for better strategies:

\subsection{Construct Better Models of Health Communication}

Because the dominant models that influence our health communication initiatives have a bias towards individual behavioral change, they remain underdeveloped with respect to important socio-cultural mediators. Bunton, Murphy \& Bennett (1991) argue that people's attitudes, values and beliefs about health are a product of social interaction. Change, especially on a population scale, involves changing collective social practices. This will require a highly sophisticated understanding of dynamic social processes that take into account the great diversity of sub-cultures in populations. Improved models will effect a "convergence" of the valuable individual, psychologically oriented concepts of traditional theory with the newer socio-cultural processes of change.

\subsection{Design Health Communication that is More "Contextual" and "Tailored"}

Both theory and empirical studies highlight the need to customize communication so that it more closely fits people's personal characteristics and social settings. Currently, much communication is delivered to the general public with "one size fits all" messages. The WHO Report notes that there is no "general public," but rather, "many publics" (WHO, 2002). Communication is often "inappropriately generalized across such factors as gender, age and culture” (Baum, 2000). This is a particular problem for people who are unable to access communication because of language, literacy or disability barriers and is thought to be a factor in the increasing health disparities in vulnerable populations worldwide. Studies using "tailored" information have demonstrated significantly improved outcomes (Kreps, 2000; Marcus, Nigg, Riebe, \& Forsyth, 2000; Rimer \& Glassman, 1997).

In addition to improving the customization of communication for individual characteristics, we must also design it so that it relates to people's social contexts. There is often an important gap between a person's knowledge and intentions to change (for example, their diet) and their ability to make that change (because of conflicting family preferences). Health interventions that involve family members have shown better outcomes than those that are only person-directed (Delameter, Bubb, Davis, Smith, Schmidt, White \& Santiago, 1990; McNabb, Quinn, Murphy, Thorp, \& Cook, 1994). Social cognitive theory posits that both learning and persuasion are enhanced when presented in situations like those in which the information is to be used (Dede and Fontana, 1995). 


\subsection{Create Health Communication to Have the Reach of Mass Media and the Impact of Interpersonal Media}

A widely held belief has been that interpersonal health communication is more effective at changing behavior, but too costly to affect large-scale populations, whereas mass media approaches have broad coverage at low-cost, but are not as effective in changing behavior (Backer, Rogers, \& Sopory, 1992). Newer studies and thinking support the understanding that both mass and interpersonal media have a synergistic effect across many social levels, and that both are necessary for behavior change in populations (Hornik, 2002). To maximize the effectiveness of health communication interventions, we suggest that strategic interventions will benefit from the coordinated use of both interpersonal and mediated communication channels. In this way, these interventions can benefit from the differential strengths of distinct communication channels, minimize the individual weaknesses of these channels, and increase message redundancy, in effect reinforcing key health promoting messages. Because people live in a multi-channel information environment, it makes sense to coordinate health-promoting information disseminated across the communication channels that members of key target audiences prefer to use.

\subsection{Improve the Interactivity of Health Communication}

The dominant form of health communication, especially that using mass media, has been one-way, from communicator to receiver. This is thought to be one explanation for the relatively modest behavioral outcomes of interventions using only mass media. Bero, Grill, Grimshaw, Harvey, Oxman, \& Thomson (1998) conclude that such passive communication is both the most common and the least effective. One-way communication may be interpreted as "authoritarian" and thus disempowering (Smedley \& Syme, 2000). Social influence theory proposes that effective communication must be both "transactional" and "user-driven" (Smith, 1982). In other words, the communication process must be one in which people voluntarily participate and grapple with their previous beliefs. Rice (2001) asserts that interactivity may be the attribute of communication with the greatest implication for health promotion, because it provides the user with control and a way to participate. This idea is supported by recent research that identifies "selfefficacy" and "perceptions of control" to be the most powerful mediators of behavioral change (Bull, Holt, Kreuter, Clark, \& Scharff, 2001). Further, an increased participation is thought to be necessary to produce "an activated motivated state" (Mittal, 1989) in which people are better able to select, interpret and respond to communication (Rubin \& Rubin, 2001).

In summary, improving health communication will involve making it more interactive, participatory, and customized to operate at personal and multiple levels of societies. We will need to advance theory and to draw upon a more powerful range of media, including new interactive channels and approaches.

\section{The Promise of E-Health Communication}

Beginning in the 1980s, many new forms of communication were created through the use of computers, other digital technologies, and the Internet. "E-health" is the general term commonly used to cover many disciplines related to information and communication technology in the health domain: medical informatics, telehealth, telemedicine, pu- 
blic health informatics, consumer informatics, and others (SPICH, 1999). Eng defines "e-health" as "the use of emerging information and communication technology, especially the Internet, to improve or enable health and health care" (Eng, 2001).

The e-health revolution has produced an ever-increasing number of new communication channels and strategies, such as: health information on the Internet, computer-assisted learning, Internet radio and television, interactive voice recognition, online support groups, online collaborative communities, information tailored by computer technologies, computer-controlled in-home telephone counseling, CD-ROMs and DVDROMs, bio-metric assessment and transmission, and patient-provider e-mail contact. It is interesting that many of these "new interactive media" are actually hybrid forms of traditional media (radio, telephone, television) combined with computer-mediated communication. Thus, in the e-health space, we are witnessing a vast merger of communication media and applications. This rapid transformation also makes it difficult to define distinct differences in traditional and e-health communication strategies. Given the greatly expanded array of digitally enabled channels and hybrid strategies, there has been great hope, and perhaps great "hype" about the potential of e-health communication to improve population health. Three aspects of e-health communication are thought to be especially promising to address the weaknesses in traditional approaches:

\subsection{Customization and Contextualization}

Many features of the new digital media enable information to be customized to people's specific interests or characteristics. Rather than receiving a generic message for the "public," people can search for highly detailed information, or find online communities of individuals like themselves via the Internet. Health professionals can use computer-based expert systems that select information from large databases and match it to a person's particular attributes or desires ("mass customization"). Channels can also be customized so that an individual can receive information according to preferences for print (fax, e-mail, letters, brochures), telephone ("pushed" messages or reminders, voice recognition), or video (CD-ROM or Web TV).

\subsection{Interactivity}

E-health is often assumed to imply "interactive" media. As noted above, such interpretations can cause confusion about definitions of traditional and new media and their applications. For example, "risk communication" can be defined as

"an interactive process of exchange of information and opinions among individu-

als, groups, and institutions. It involves multiple messages about the nature of risk

and other messages, not strictly about risk, that express concerns, opinions, or re-

actions to risk messages or to legal and institutional arrangements for risk man-

agement. "(National Research Council, 1989, page 21).

In the evolving international conceptualization of "e-health," risk communication using interactive electronic communication technologies, especially those that are computermediated, could be described as "e-health risk communication." Certainly e-health communication provides greatly increased opportunities for people to interact with information, health professionals and each other. It enables mass media to be transformed from one-way passive communication, to highly transactional processes that allow people to participate at their own convenience (“24/7”) and to interact with other people through chat rooms, list serves, and online communities. Heightened interactivity 
and participation are hypothesized to increase self-efficacy and sense of control, the strongest known mediators of behavioral change.

\subsection{Expanded and Mixed Media Channels}

Digital technologies have catalyzed an explosion in new media channels and perhaps limitless potential communication strategies. E-health communication includes many new communication channels as described above, as well as mixes of traditional media, and traditional and new media. One outcome is that mass and interpersonal features can now be combined - as a "hybrid medium" - in communication initiatives. For example, a health care organization can send highly personalized information to patients en masse. Likewise, patients can query their health providers at their convenience and in their own words. People with rare diseases can create online communities and even set up collaborative research programs. People can be developers as well as receivers of information. The Internet is the first "many to many" medium in history. The impact of the transformation of much health communication from passive, generic, and expert-driven to highly personalized, interactive and often user-driven is hard to fathom. Walther (1996) believes it is an entirely new phenomenon - "hyperpersonal communication" - and Caplan (2001) suggests that the potential of the radically new media have power beyond our understanding. We propose that the power lies in the ability to link many media synergistically and extend interactive communication globally.

Each medium has unique communicative properties that can influence health promotion efforts (Kreps, 1988). For example, face-to-face interpersonal communication has a high level of immediacy, attracts attention, and is adaptive. However, information exchanged in such face-to-face communication flashes by quickly, and can be easily forgotten or misconstrued. Print media, such as books or pamphlets, may not always be very exciting, but these media allow audiences to review messages as often as needed to increase understanding and recall. Mass media, such as film and television, can be very dramatic and emotion provoking, although they are not always good channels for conveying complex or technical information. New media, such as e-mail systems and the Internet, can combine the benefits of interpersonal, print, and mass media, enabling dynamism, interactive adaptability, and permanence for later review. It is our contention that e-health interventions can profitably use new media synergistically, in combination with other communication channels, to effectively communicate health promotion messages.

\section{Initial Experimental Outcomes of E-Health Communication}

E-health communication clearly has the theoretical ability to transform health communication. Whether this will result in the desired health outcomes is now a matter of intensive research. The evaluation of interactive media has posed important research challenges (Eng, 2002; Kreps, 2002). Research involving interactive media will require new methods, research design and statistical models. For example, in tailored communication studies in which no two subjects receive the exact same intervention, it is difficult for researchers to attribute outcomes to a specific intervention or to define common mediating variables.

Overall, the results of the first decade of e-health communication studies have been positive, especially in the areas of shared decision-making and tailored communication. In shared decision-making interventions, patients have access to specialized information 
mediated by computers. Tailored communication is customized to an individual's personal characteristics. These two approaches often overlap and can involve a mix of media, as in telephone counseling controlled by computer. In addition to counseling, ehealth telephone interventions can include computer-generated voice response, reactive helplines, and motivational interviews. Kreps' (2000) review of 141 tailored message interventions found that telephone-delivered tailored messages generally showed better outcomes than tailored print materials. As a further example of the power of mixed media, Rimer et al. (2001) concluded that combining tailored print and telephone-delivered interventions can be highly effective. Positive outcomes are not limited by communication channel.

Revere and Dunbar (2001) found significant results for 12 of 37 randomized controlled clinical trials and quasi-experimental trials using computer-tailored information delivered by a variety of devices. For example, one of these studies using tailored, automated telephone conversations showed that it significantly increased medication adherence and decreased blood pressure in the patient intervention vs. control group (Friedman, 1998). In addition, patients using this "remote telephone-linked care" system decreased cholesterol levels (no change in controls) and significantly increased the weekly amount of walking they did as compared with that of the controls. Another study included in Revere and Dunbar's review found that younger smokers were more likely to quit if they received a letter tailored to their stage of "readiness to change" vs. a generic letter (Strecher et al., 1994).

Research is demonstrating how e-health interventions can harness the power of $\mathrm{mul}$ tiple media for better health outcomes. For example, Shegog et al. (2001) described a computer-assisted education program to help urban, minority children (aged 9-13 years) improve their management of asthma. The children used an interactive program to learn about asthma symptoms, triggers, taking medication, and getting help. The program included tailored text, animation, sound and video clips and a game with 18 realworld and 4 fantasy situations for the children to master. The study results showed that children in the intervention group scored significantly higher on knowledge about selfregulation, prevention and treatment of their asthma than a randomized control group of children who did not use the program. Intervention children also scored higher on the important mediating factor of self-efficacy and had a lower rate of hospitalizations for asthma.

Most studies of computer-based education show that they are well accepted by patients and result in improved health (Krishna, Balas, Spencer, Griffen \& Boren, 1997). Lewis' review (1999) of computer-mediated education between 1971 and 1998 showed positive results for 16 of 21 studies. It is notable that successful outcomes are being found for a wide range of health factors. Such programs have been shown to help patients control cholesterol levels (Dutton, Posner, Smigelski, Noonan \& Friedman, 1995) and hypertension (Friedman et al., 1996). E-health interventions are proving effective even for very hard to change behaviors like diet and physical activity. Marcus, Heimendinger et al. (1998) reported that tailored messages improved fruit and vegetable intake. Marcus, Emmons and Simkin-Silverman et al. (1998) found that tailored materials were more effective than standard interventions to improve physical activity. Weight loss interventions that used computer-customized materials were significantly more effective than those using non-tailored materials (Bull et al. 2001). In a review of 80 clinical trials of ehealth communication between patients and providers, 63 percent demonstrated significant outcomes for diabetes, osteoarthritis and other conditions (Balas et al., 1997).

It is especially encouraging that e-health approaches are demonstrating positive re- 
sults among ethnically diverse and low-income populations. Lipkus, Lyna, \& Rimer (1999) reported that a smoking cessation intervention using tailored information was successful among low-income African-Americans. Likewise, there is now more than a decade of successful study outcomes from the Comprehensive Health Enhancement Support System (CHESS) intended to help women with breast cancer or people with AIDS to access computer-mediated information about making medical decisions and finding support groups (Gustafson, Julesberg et al., 2001; Gustafson, Hawkins et al., 1999). Specifically, CHESS includes integrated information, referral, decision and support programs. Women using the system can talk anonymously with other women, ask experts questions, learn where to get help and how to use health care, access articles, read stories from other women with breast cancer and get help to make decisions. Women subjects reported high usage of CHESS and that it improved their feelings of empowerment and motivation and reduced negative emotions such as fear, stress and anger. Study findings showed that CHESS was effective for both low-income, lower-educated women, as well as those with higher education and income. In another randomized controlled study of people with HIV/AIDS, the CHESS group showed reduced health care visits and hospitalizations as compared with the control group outcomes (Gustafson, Hawkins et al., 1999).

\subsection{Current E-Health Communication Access and Use}

For most people worldwide, e-health communication is currently limited to their use of the Internet. There are few people with access to the diverse kinds of e-health communication cited in the preceding studies.

In 2002, Global-Reach (2002a) estimated the number of international Internet users at 619 million. Although English has been the dominant language of the Internet, online non-English-speaking populations are projected to double from 400 million in 2002 to 800 million in 2005 (Global-Reach, 2002b). The growth of Internet access and use is extraordinary. In the United States, for example, Internet use grew to approximately 174 million in 2001 (66\% of the population). This represents an increase of 26 million users in only 13 months. (NTIA, 2002)

Health information is a priority for Internet users. In the US in February 2003, 78\% of 109 million online users (52\% of all US adults) searched for health information online. (Harris Interactive, 2003). Users primarily searched for information about immediate health problems (91\%); only 13\% looked for ways to prevent health problems. The vast majority of users have access to e-health information in the form of the Internet as a database, and very few have access to interactive health applications such as online support groups, connections with their health providers, multi-media information with video or audio, or ways to send their measurements of body metrics (like blood glucose or blood pressure) to their health care providers.

Despite the limited access to e-health applications, it appears that people who use the Internet for health information are enthusiastic about this communication. Eysenbach \& Köhler's (2002) qualitative study in Germany found high satisfaction among participants who searched the Internet for health information; subjects were able to successfully find the desired information in an average of only 6 minutes. In a US study, half of the people who responded to a survey about health information on the Internet reported that they made changes in their diet or physical activity because of Internet advice (Fox et. al., 2000). Although their responses could not be scientifically validated, they are indicative of the value people place on Internet health information. 


\subsection{Comparing Experimental Outcomes and Actual Use of E-Health Communication}

The early study outcomes of e-health communication are promising. The new media and increased extension and interactivity of traditional media appear to significantly improve behavioral outcomes. The encouraging results come with important caveats. So far, the experimental studies are small, short-term and not representative of large, diverse populations. And, because most people do not usually have access to the kind of interactive health communication used in the studies, it is uncertain whether e-health communication will have the power to motivate and sustain behavior change on a population basis. Furthermore, even among people with access to powerful e-health communication, the aforementioned methodological limitations make it difficult to discern the specific mediating variables that facilitate positive outcomes.

\section{The Future of E-Health Communication}

The future prospects for e-health communication will be determined less by positive experimental outcomes than by the larger issues of global population access and use, national leadership initiatives, and public-private partnerships to develop e-health applications using mixed and interactive media. Such collaboration is needed to implement large-scale, population-level health communication interventions.

\subsection{E-Health Communication and National Initiatives}

It is apparent that people worldwide are embracing e-health communication in the form of Internet information in exponentially increasing numbers. Although subjective satisfaction is a positive indicator, it does not predict whether e-health communication will have a significant impact on the ultimate goal of improving population health. Communication scholars have identified important barriers to reaching this goal.

Limited accessibility of Internet information is a major problem for people who speak languages other than English, have low literacy, or a disability that limits accessibility. Currently, it is estimated that, worldwide, $80 \%$ of websites are in English (Jupiter Intermedia Communications, 2002) although 64\% of users are not native English speakers (Global-reach, 2002b). Because many people with visual and other disabilities have difficulty using current websites, the international World Wide Web Consortium was established to provide technical guidance for the design of accessible sites (W3C, 1999). In 1998, the US government passed legislation requiring that federal agencies make their electronic and information technology accessible to people with disabilities (Davis, 2002). Difficult Web navigation and content at high reading levels also pose barriers for large numbers of low-literate Internet users (Zarcadoolas, Blanco, \& Boyer, 2002).

Another concern is the quality (and confidentiality) of information available on the Internet where "anyone can be a publisher" (Horrigan, 2002; Karp \& Monroe, 2002). There are a number of international efforts to define quality standards and guide consumers. The WHO has requested that the Internet Corporation for Assigned Names and Numbers (ICANN) that approves Internet domain names, develop a "health" domain to signal to users that certain health sites meet agreed upon standards for accuracy and safety (Brown, 2002). The European Commission has published a code of good practice for websites that defines standards for honesty about the site provider, sources and dating of information, privacy and confidentiality, accountability, usability, and other features (Watson, 2002). Accredited sites could apply for a "EuroSeal" of quality. The G8 
initiated the Global Healthcare Applications Project in part to promote joint approaches to setting e-health standards (Dietzel, 1999). Healthcare organizations in Germany have called for a "uniform health platform" ("Aktionsforum Telematik im Gesundheitswesen”) to improve quality in the telemedicine sector (Zipperer, 2001).

Increasingly, governments are developing their own quality-controlled health websites. In Germany, the CancerNet was created to provide people with accurate, updated information about cancer therapies. Since 1994, 2 million people, including 200,000 physicians have used the site and rated it "excellent" or "good" (Quade, Burde, Zenker \& Goldschmidt, 2000). The United Kingdom’s National Health Service Direct Online is intended to provide credible and updated information to the entire NHS population (Eaton, 2002). Canada's national health site is http://www.canadian-health-network.ca, and two US government sites are http://healthfinder.gov/ and http://www.cancer.gov/.

While there are strong international initiatives to improve labeling of websites and development of high-quality national sites, there has been less national leadership to advance access to the kind of interactive e-health communication studied experimentally. Cassell et al. (1998) suggest that it is likely that public health professionals view the Internet primarily as a virtual clearinghouse for information. They do not yet perceive that with a greater media mix and interactivity, it could be a powerful global communication channel to facilitate large-scale behavior change. Even if nations understand the value of extensive, interactive health media, the applications still need to be developed. However, according to Eng (2001), there are few sustainable e-health revenue models outside of those for clinical care. Fisher (1995) concludes that because "free market forces" are not sufficient to develop e-health applications in the near term, government support is essential to promote highly effective communication.

\section{Conclusions: E-Health Communication}

The primary global challenge to large-scale public health promotion is to facilitate behavior change on a population level. Strategic health communication interventions have the potential to influence a broad range of important health behaviors to improve public health at individual, group, and population levels. The emergence of new media applications in health promotion increases the scope of health communication interventions, especially when these new channels of communication are effectively integrated with other, more traditional, communication media. We suggest that to maximize the effectiveness of health communication interventions, interpersonal, mass media, and new media channels should be carefully coordinated so they support and reinforce important health promotion messages. E-health communication, mediated by computers and other digital technologies, has the potential to extend and amplify the impact of traditional health promotion media by linking, personalizing, and expanding the coverage of health promotion messages. The long-term success of multi-channel health communication interventions will depend on collaborative efforts to articulate the use of new and traditional communication channels, rigorous research to guide the application of strategic communication interventions, and the continuing development of new and powerful communication technologies and applications. 


\section{References}

Airhihenbuwa, C. O., \& Obregon, R. (2000). A critical Assessment of theories/models used in health communication for HIV/AIDS. Journal of Health Communication, 5, (Supplement), $5-15$.

Backer, T. E., Rogers, E. M., \& Sopory, P. (1992). Designing health communication campaigns: What works? Newbury Park, CA: Sage.

Balas, E. A., Jaffrey, F., Kuperman, G. J., Boren, S. A., Brown, G. D., Pinciroli, F., \& Mitchell, J. A. (1997). Electronic communication with patients: Evaluation of distance medicine technology. Journal of the American Medical Association, 278, 152 - 159.

Baum, A. (2000). Behavioral and psychosocial interventions to modify pathophysiology and disease course. In B. Smedley, \& S. L. Syme (Eds.), Promoting health: Intervention strategies from social and behavioral research (pp. 450 - 488). Institute of Medicine. Washington, DC: National Academy Press.

Bero, L. A., Grill, R., Grimshaw, J. M., Harvey, E., Oxman, A. D., \& Thomson, M. A. (1998). Closing the gap between research and practice: An overview of systematic reviews of interventions to promote the implementation of research findings. British Medical Journal, 317, 465 - 468.

Brown, P. (2002). WHO calls for a health domain name to help consumers. British Medical Journal, (News), (9 March) 324, 566.

Bull, F. C., Holt, C. L., Kreuter, M. W., Clark, E. M., \& Scharff, D. (2001). Understanding the effects of printed health education materials: Which features lead to which outcomes? Journal of Health Communication, 6, 265 - 279.

Bunton, R., Murphy, S., \& Bennett, P. (1991). Theories of behavioural change and their use in health promotion: Some neglected areas. Health Education Research, 6(2), 153-162.

Caplan, S. (2001). Challenging the mass-interpersonal communication dichotomy: Are we witnessing the emergence of an entirely new communication system? The Electronic Journal of Communication/La Revue Electronique de Communication, 11(1).

Cassell, M. M., Jackson, C., \& Cheuvront, B. (1998). Health communication on the Internet: An effective channel for health behavior change? Journal of Health Communication, 3, 71 - 79.

Davis, J. J. (2002). Disenfranchising the disabled: The inaccessibility of Internet-based health information. Journal of Health Communication, 7, 355 - 367.

Dearing, J. W., Rogers, E. M., Meyer, G., Casey, M. K., Rao, N., Campo, S., \& Henderson, G. M. (1996). Social marketing and diffusion-based strategies for communicating with unique populations: HIV prevention in San Francisco. Journal of Health Communication: International Perspectives, 1(4), $342-364$.

Dede, C., \& Fontana, L. (1995). Transforming health education via new media. In L. M. Harris (Ed.), Health and the new media: Technologies transforming personal and public health (pp. 163-183). Hillsdale, NJ: Erlbaum.

Delamater, A. M., Bubb, J., Davis, S. G., Smith, J. A., Schmidt, L., White, N. H., \& Santiago, J. V. (1990). Randomised prospective study of self-management training with newly diagnosed diabetic children. Diabetes Care, 13, 492 - 498.

Dietzel, G. (1999). The G8-global healthcare applications project (GHAP) - recommendations for the way into the information society. EurJ Med Res, Dec 16; 4(12), 533 - 6.

Dutton, J. P., Posner, B. A., Smigelski, C., Noonan, J., Friedman, R. H. (1995). Use of an automated telephone counselor to reduce serum lipids in hypercholesterolemia. (18th Annual Meeting of the Society of General Internal Medicine San Diego, California, USA May 4 -6, 1995) Journal of General and Internal Medicine, 10(4 Suppl.), 99.

Eaton, L. (2002). UK government aims to integrate health information on the Internet. British Medical Journal, (March 9) 7337, 566.

Emmons, K. M. (2000). Behavioral and social science contributions to the health of adults in the United States. In B. Smedley, \& S. L. Syme (Eds.), Promoting health: Intervention strategies from social and behavioral research (pp. 254 - 321). Institute of Medicine. Washington, DC: National Academy Press.

Eng, T. R. (2001). The eHealth landscape: A terrain map of emerging information and communica- 
tion technologies in health and health care. Princeton, NJ: The Robert Wood Johnson Foundation.

Eng, T. R. (2002). eHealth research and evaluation: Challenges and opportunities. Journal of Health Communication, 7, $267-272$.

Epp, J. (1986). Achieving health for all: A framework for health promotion. Ottawa National Health and Welfare, Government of Canada.

Eysenbach, B. \& Köhler, C. (2002). How do consumers search for and appraise health information on the World Wide Web? Qualitative study using focus groups, usability tests, and in-depth interviews. British Medical Journal, 324(7337), 9 March 2002, 573 - 577.

Ferguson, J. (1998). Health behavior. In R. B. Wallace and B. N. Doebbeling (Eds.), Maxcy-Rosenau-Last Public health E preventive medicine (pp. 811 - 816). Stamford, Connecticut: Appleton \& Lange.

Fisher, F. D. (1995). But will the new health media be forthcoming? In L. Harris (Ed.), Health and the new media: Technologies transforming personal and public health (pp. 209-227). Mahwah, NJ: Lawrence Erlbaum.

Flora, J. A., Maccoby, N., \& Farquhar, J. W. (1989). Communication campaigns to prevent cardiovascular disease: The Stanford community studies. In R. E. Rice \& C. K. Atkin (Eds.), Public Communication Campaigns, 2nd edition (pp. 233 - 252). Newbury Park, CA: Sage.

Fox, S., Rainie, L., Horrigan, J., Lenhart, A., Spooner, T., Burke, M., Lewis, O., \& Carter, C. (2000). The online health care revolution: How the Web helps Americans take better care of themselves. Pew and the American Life Project. Report retrieved November 2000 from http://www. perinternet.org/reports.

Friedman, R. H. (1998). Automated telephone soncersations to assess health behavior and deliver behavioral interventions. J Med Syst., 22, $95-102$.

Friedman, R. H., Kazis, L. E., Jette, A., Smith, M. B., Stollerman, J. Torgerson, J., \& Carey, K. (1996). A telecommunications systems for monitoring and counseling patients with hypertension. Impact on medication adherence and blood pressure control. American Journal of Hypertension, 9(4 Pt 1), 285 - 292.

Gobal-Reach (2002a). http://www.global-reach.biz/globstats/index.php3, posted on the Internet 22 November, 2002.

Global-Reach (2002b). http://www.global-reach.biz/globstats/evol.html, posted on the Internet 22 November, 2002.

Greenfield, S., Kaplan, S., \& Ware, J. Jr. (1985). Expanding patient involvement in care: Effects on patient outcomes. Annals of Internal Medicine, 102, 520 - 528.

Gustafson, D. H., Hawkins, R., Boberg, E., Pingree, S., Serlin, R. E., Graziano, F., \& Chan, C. L. (1999). Impact of a patient-centered, computer-based health information/support system. American Journal of Preventive Medicine, 16(1), 1 - 9.

Gustafson, D. H., Julesberg, K. E., Stengle, W. A., McTavish, F. M., \& Hawkins, R. (2001). Assessing costs and outcomes of providing computer support to underserved women with breast cancer: A work in progress. The Electronic Journal of Communication/La Revue Electronique de Communication, 11, (3 \& 4).

Harris Interactive (2003). No Significant Change in the Numbers of "Cyberchondriacs» - Those Who Go Online for Health Care Information, Says Latest National Survey. Report posted on the Internet on March 28, 2003. http://www.harrisinteractive.com/news/allnewsbydate. asp?NewsID $=600$ or http://www.harrisinteractive.com/news/newsletters_healthcare.asp

Hornik, R. C. (2002). Public health communication: Evidence for behavior change. Mahwah NJ: Lawrence Erlbaum Associates, Inc.

Horrigan, J. B. (2002). Getting serious online. Pew and the American Life Project. Report retrieved March 3, 2002 from http://www.perinternet.org/reports.

Institute of Medicine (2001). Health and behavior: The interplay of biological, behavioral and societal influences. Washington, DC: National Academy Press.

Jupiter Intermedia Corporation (2002). CyberAtlas: Worlds online populations. Posted on the Internet, 22 November 2002: http://cyberatlas.internet.com/big_picture/geographics/article/ 0,5911_151151,00.html 
Karp, S., \& Monroe, A. F. (2002). Quality of healthcare information on the Internet: Caveat emptor still rules. Managed Care Quarterly, 10(2), 3-8.

Kreps, G. L. (1988). The pervasive role of information in health care: Implications for health communication policy. In J. Anderson (Ed.), Communication yearbook (pp. 238 - 276). Newbury Park, CA: Sage.

Kreps, G. L. (2000). The role of interactive technology in cancer communications interventions: Targeting key audience members by tailoring messages. Paper presented to the American Public Health Association conference, Nov., Boston.

Kreps, G. L. (2002). Evaluating new health information technologies: Expanding the frontiers of health promotion and health care delivery. In R. G. Bushko (Ed.), The future of health technology, (pp. 205 - 212). Amsterdam: OIS Press.

Kreps, G. L., \& Chapelsky Massimilla, D. (2002). Cancer communications research and health outcomes: Review and challenge. Communication Studies, 53(4), 318 - 336.

Kreps, G. L., \& O’Hair, D. (Eds.). (1995). Communication and health outcomes. Cresskill, NJ: Hampton Press.

Kreps, G. L., Bonaguro, E. W., \& Query, J. L. (1998). The history and development of the field of health communication. In L. D. Jackson and B. K. Duffy (Eds.), Health communication research, A guide to developments and directions (pp. 1 - 15). Westport, CT: Greenwood Press.

Krishna, S., Balas, E. A., Spencer, D. C., Griffen, J. Z., \& Boren, S. A. (1997). Clinical trials of interactive computerized patient education: Implications for family practice. Journal of Family Practice, 45(1): 25 - 33 .

Lewis, D. (1999). Computer-based approaches to patient education. Journal of the American Medical Informatics Association, 6, 272 - 282.

Lipkus, I., Lyna, P., \& Rimer, B. (1999). Using tailored interventions to enhance smoking cessation among African-Americans at a community health center. Nicotine and Tobacco Research, 1, $77-85$

Marcus, A. C., Heimendinger, J., Wolfe, P., Rimer, B. K., Morra, M., Cox, D., Lang, P. J., Stengle, W, an Herle, M. P., Wagner, D., Fairclough, D., \& Hamilton, L. (1998). Increasing fruit and vegetable consumption among callers to the CIS: results from a randomized trial. Preventive Medicine, Sep-Oct; 27 (5 Pt 2), 16 - 28.

Marcus, B. H., Emmons, K. M., Simkin-Silverman, L. R. et al. (1998). Evaluation of motivationally tailored vs. standard self -help physical activity interventions at the workplace. AmJ Health Promotion, 12, $246-53$.

Marcus, B. H., Nigg, C. R., Riebe, D., \& Forsyth, L. H. (2000). Interactive communication strategies: Implications for population-based physical activity promotion, American Journal of Preventive Medicine, 19(2), $121-126$.

McGinnis J. M. \& Foege, W. H. (1993). Actual causes of death in the United States. Journal of the American Medical Association, 270(18): 2207 - 2211

McNabb, W. L., Quinn, M. T., Murphy, D. M., Thorp, F. K., \& Cook, S. (1994). Increasing children's responsibility for diabetes self-care: The In Control study. Diabetes Educator, 20, 121 124.

Mittal, B. (1989). A theoretical analysis of two recent measures of involvement. Advances in Consumer Research, 16, 697- 702.

National Research Council (1989). Improving risk communication. Washington, DC: National Academy Press.

National Telecommunications and Information Administration (NTIA). (February 2002). A nation online: How Americans are expanding their use of the Internet. Washington, D.C. http://www.ntia.doc.gov/ntiahome/dn/index.html.

Neuhauser, L., \& Kreps, G. L. (2003). Rethinking communication in the e-health era. Journal of Health Psychology, 8(1), $7-22$.

Pavlik, J. V., Finnegan, J. R., Strickland, D., Salman, C. T., Viswanath, K., \& Wackman, D. B. (1993). lncreasing public understanding of heart disease: An analysis of the Minnesota Heart Health program. Health Communication, 5(1), 1-20. 
Quade, G., Burde, B., Zenker, S., \& Goldschmidt, A. (2000). CancerNet online - a contribution to improving oncologic management. Zentralbl Gynakol, 122(12), $646-50$.

Revere, D., \& Dunbar, P. J. (2001). Review of computer-generated outpatient health behavior interventions: clinical encounters "in absentia". Journal of the American Medical Informatics Association, $8,62-79$.

Rice, R. E. (2001). The Internet and health communication: A framework of experiences. In R. E. Rice \& J. E. Katz (Eds.). The Internet and health communication (pp. 5-46). Thousand Oaks, CA: Sage.

Rimer, B. K., Halabi, S., Skinner, C. S., Kaplan, E. B., Crawford, Y., Samsa, G. P., Strigo, T. S., \& Lipkus, I. M. (2001). The short-term impact of tailored mammography decision-making interventions. Patient Education and Counseling, 43(3), 217 - 287.

Rimer, B., \& Glassman, B. (1997). Tailored communication for cancer prevention in managed care settings. Outlook, $4-5$.

Rogers, E. M. (1995). Diffusion of innovations. (Fourth Edition). New York: Free Press.

Rubin, A., \& Rubin, R. (2001). Interface of personal and mediated communication: Fifteen years later. The Electronic Journal of Communication/La Revue Electronique de Communication, 11(1), December 13.

Science Panel on Interactive Communication and Health (SPICH) (1999). Wired for health and well-being: The emergence of interactive health communication. Eng, T. R. \& Gustafson, D. H. (Eds.), Washington, DC: U.S. Department of Health and Human Services, U.S. Government Printing Office.

Shegog, R., Bartholomew, K., Parcel, G. S., Sockrider, M. M., Masse, L., Abramson, S. L. (2001). Impact of a computer-assisted education program on factors related to asthma self-management behavior. Journal of the American Medical Association, 8(1), 49-61.

Smedley, B., \& Syme, S. L. (Eds.) (2000). Promoting health: Intervention strategies from social and behavioral research. Institute of Medicine. Washington, DC: National Academy Press.

Smith, M. J. (1982). Persuasion and human action: A review and critique of social influence theories. Belmont, CA: Wadsworth.

Snyder, L. B., \& Hamilton, M. S. (2002). A meta-analyses of US health campaign effects on behavior: Emphasize enforcement, exposure, and new information, and beware the secular trend. In R. C. Hornik (Ed.), Public health communication: Evidence for behavior change (pp. 357 - 383). Mahwah, NJ: Lawrence Erlbaum Associates.

Stokals, D. (2000). The social ecological paradigm of wellness promotion. In M. S. Jamner and D. Stokals (Eds.), Promoting human wellness: New Frontiers for research, practice, and policy (pp. 21 - 37). Berkeley, Los Angeles, and London: University of California Press.

Strecher, V. J., Kreuter, M., Den Boer, D. J., Kobrin, S., Hospers, H. J., Skinner, C. S. (1994). The effects of computer-tailored smoking cessation messages in family practice settings. J Fam Pract., 39, $262-70$.

US Department of Health and Human Services (USDHHS) (2000). Healthy People 2010: Conference edition in two volumes. Washington, DC: U.S. Government Printing Office.

Walther, J. B. (1996). Computer-mediated communication: Impersonal, interpersonal, and hyperpersonal interaction. Communication Research, 23, 3-43.

Watson, R. (2002). European Commission to publish a code of practice for websites. British Medical Journal, (News), (9 March), 324 - 327.

Weinstein, N. (1993). Testing four competing theories of health-protective behavior. Health Psychology, 12, $324-333$.

World Health Organization (WHO) (2002). The World Health Report 2002: Reducing risks, promoting bealthy life. Geneva.

World Health Organization. (1998). Report on Health Promotion: Milestones on the road to a global alliance. Fact Sheet No 171, http://www.who.int/inf-fs/en/fact171.html.

World Wide Web Consortium (W3C) (1999). List of checkpoints for web content accessibility guidelines 1.0, available online at http://www.w3.org/TR/WAI-WEBCONTENT/checkpointlist.html. 
Yoder, O. S., Hornik, R., \& Chirwa, B. C. (1996). Evaluating the program effects of a radio drama about AIDS in Zambia. Studies in Family Planning, 27(4), 188 - 203.

Zarcadoolas, C., Blanco, M., \& Boyer, J. F. (2002). Unweaving the Web: An exploratory study of low-literate adults' navigation skills on the World Wide Web. Journal of Health Communication, 7, 309-324.

Zipperer, M. (2001). Das Aktionsforum Telematik im Gesundheitswesen. Telemedizinführer Deutschland 2001. Ober Mörlen: Deutsches Medizin Forum. 